\title{
Avaliação do Valor Nutritivo da Planta e da Silagem de Diferentes Híbridos de Sorgo (Sorghum bicolor, L. Moench) ${ }^{1}$
}

\author{
Mikael Neumann ${ }^{2}$, João Restle ${ }^{3}$, Dari Celestino Alves Filho ${ }^{4}$, Ivan Luiz Brondani ${ }^{5}$, \\ Luis Giovani de Pellegrini ${ }^{6}$, Aline Kellermann de Freitas ${ }^{7}$
}

\begin{abstract}
RESUMO - O experimento foi conduzido com o objetivo de avaliar o valor nutritivo do material original e da silagem de diferentes híbridos de sorgo: AGX-213, AG-2002, AGX-217 e AG-2005E. O híbrido AG-2005E foi mais precoce (125 dias) de intervalo da semeadura à colheita, enquanto o AGX-213, o mais tardio (151 dias). Os híbridos forrageiros AG-2002 e AGX-213 apresentaram maiores alturas de planta e produções de matéria seca que os de duplo propósito AGX-217 e AG-2005E. O híbrido AG-2005E apresentou maior porcentagem de panícula $(58,4 \%)$ e baixa porcentagem de colmo $(20,1 \%)$ e folhas $(21,5 \%)$ na composição da planta, enquanto os híbridos forrageiros (AGX-213 e AG-2002), as maiores proporções do componente colmo, 45,1 e 56,8\%, respectivamente. Os teores de matéria seca na planta não foram alterados com o processo de ensilagem. Não houve diferença entre as silagens para os teores de fibra em detergente neutro, lignina e cinzas totais na fibra em detergente ácido. A silagem do AG-2005E apresentou menor teor de fibra em detergente ácido (28,96\%) e celulose $(24,19 \%)$ e maior concentração de matéria seca $(35,50 \%)$ frente aos demais híbridos. Não houve diferença entre as silagens dos híbridos de sorgo para os teores de matéria orgânica, digestibilidade in vitro da matéria orgânica e concentração de energia digestível. A porcentagem de nutrientes digestíveis totais foi maior para os híbridos de duplo propósito AG-2005E (62,20\%) e AGX-217 (60,05\%), comparativamente aos forrageiros AGX-213 (56,77\%) e AG-2002 (56,40\%).
\end{abstract}

Palavras-chave: digestibilidade, sorgo forrageiro, sorgo duplo propósito, valor nutritivo

\section{Nutritional Evaluation of the Plant and Silage of Different Sorghum Hybrids (Sorghum bicolor, L. Moench)}

\footnotetext{
ABSTRACT - The experiment was conducted with the purpose to evaluate the nutritional value of the plant and silage of different sorghum hybrids: AGX-213, AG-2002, AGX-217 e AG-2005E. The AG-2005E hybrid was the most precocious with 125 days between sowing and harvesting, while the AGX-213 was the latest with 151 days. The plants of the forage hybrids AG-2002 and AGX-213 were taller and showed higher dry matter production than the double purpose hybrids AGX-217 and AG-2005E. The AG-2005E hybrid plant showed higher panicle percentage (58.4\%) and lower percentages of stem (20.1\%) and leaves (21.5\%), while the forage hybrids AGX-213 and AG-2002 showed higher stem percentage, 45.1 and 56.8\%, respectively. The plant dry matter contents did not change with silage fermentation. No differences were observed among the silages of the sorghum hybrids for the content of neutral detergent fiber, lignin and total ash in ADF. The AG-2005E silage presented lower values of acid detergent fiber (28.96\%) and cellulose (24.19\%) and higher content of dry matter (35.50\%) in comparison with the other hybrids. No differences were observed among the silages of sorghum hybrids for organic matter, in vitro organic matter digestibility and digestible energy concentration. The percentage of TDN was higher for the double purpose hybrids AG-2005E (62.20\%) and AGX-217 (60.05\%) than for the forage hybrids AGX-213 (56.77\%) and AG-2002 (56.40\%).

Key Words: digestibility, double purpose sorghum, forage sorghum, nutritional value

\section{Introdução}

O uso de silagem como volumoso é uma prática bastante conhecida dos terminadores de bovinos de corte em confinamento. Entre as espécies forrageiras que podem ser ensiladas, o sorgo (Sorghum bicolor, L. Moench) destaca-se por ser um alimento de alto valor

nutritivo, que apresenta alta concentração de carboidratos solúveis essenciais para adequada fermentação láctica, bem como altos rendimentos de matéria seca por unidade de área (Silva \& Restle, 1993) e boa adaptação às variadas condições de solo e clima do Rio Grande do Sul.

No sistema organizacional e de planejamento das empresas rurais, a escolha de híbridos de sorgo para

${ }^{1}$ Parte da Dissertação de Mestrado do primeiro autor. Pesquisa parcialmente financiada pela FAPERGS.

2 Eng $^{\circ}-$ Agr $^{\circ}$, MSc.

${ }^{3}$ Eng - Agro , Ph.D., Pesquisador do CNPq, Professor Titular do Departamento de Zootecnia da UFSM - Campus Camobi, 97119-900, Santa Maria - RS

E mail: jorestle@ccr.ufsm.br

${ }^{4}$ Eng $^{\circ}$-Agro ${ }^{\circ}$, MSc., Professor do Departamento de Zootecnia da UFSM. E.mail: dcafilho@ccr.ufsm.br

5 Zootecnista, MSc., Professor do Departamento de Zootecnia da UFSM. E.mail: brondani@ccr.ufsm.br

${ }^{6}$ Bolsista PIBIC-CNPq, Aluno do curso de Medicina Veterinária da UFSM.

${ }^{7}$ Bolsista IC-FAPERGS, Aluna do curso de Zootecnia da UFSM.
} 
produção de silagem tem sido bastante controvertida, devido à falta de informações quanto ao comportamento agronômico produtivo e qualitativo de diferentes materiais genéticos ofertados pelas empresas de melhoramento e multiplicação genética. As opções de cultivares de sorgo com índices de produtividade e adaptação são diversificadas. Segundo Zago (1991), a caracterização agronômica dos materiais genéticos disponíveis no mercado é de fundamental importância, para se obter uma silagem de sorgo de alta produção e com elevado valor nutritivo. Conforme Almeida Filho et al. (1999), a identificação de plantas mais adaptadas às condições em que serão cultivadas contribuirá para obtenção de maiores rendimentos da cultura do sorgo, pois ressalta-se que, além da genética e do ambiente, a produção é influenciada, entre outros fatores, por qualidade da semente, época de semeadura, população de plantas, preparo, correção e adubação do solo, irrigação, controle de plantas daninhas, pragas e doenças. Contudo, existem poucas informações sobre os efeitos destes fatores sobre a qualidade da forragem produzida.

Atualmente, os componentes dos constituintes da parede celular fibra em detergente neutro (FDN), fibra em detergente ácido (FDA) e lignina são referências fundamentais para os sistemas modernos de predição de ganhos, como o NRC (1996). Eifert (2000) relata que numerosos estudos demonstraram relação negativa entre FDN e consumo de matéria seca e entre FDA e digestibilidade aparente.

Segundo Brondani et al. (2000), a otimização de sistemas intensivos de produção pecuária depende da produção de silagem de baixo custo e alto valor nutritivo, para que o giro de capital investido seja feito no menor tempo possível.

Os híbridos de sorgo AG-2002 e AG-2005E encontram-se no mercado há vários anos, enquanto os híbridos AGX-213 e AGX-217 recentemente foram lançados pela empresa de melhoramento, no intuito de suprir as necessidades dos produtores com relação a materiais com melhores características para produção de silagem de qualidade, visando substituiros materiais mais antigos. Assim, de maneira geral, estudos de comparação entre híbridos são importantes para contribuir com os programas de melhoramento genético e para recomendar aos produtores os híbridos ou cultivares cujas silagens tenham a melhor relação produção:valor nutritivo.

Este trabalho foi realizado com o objetivo de avaliar o comportamento agronômico quantitativo e o valor nutritivo da planta inteira e da silagem de híbridos de sorgo de caráter forrageiro ou de duplo propósito.

\section{Material e Métodos}

O experimento foi conduzido no Setor de Bovinocultura de Corte do Departamento de Zootecnia da Universidade Federal de Santa Maria, localizada fisiograficamente na Depressão Central do Estado do Rio Grande do Sul, a uma altitude de $95 \mathrm{~m}$. Cartograficamente se localiza a $29^{\circ} 43^{\prime}$ de latitude Sul e 5342' de longitude Oeste. O clima da região é o Cfa (subtropical úmido), conforme classificação de Köppen, com precipitação média anual de $1.769 \mathrm{~mm}$, temperatura média anual de $19,2^{\circ} \mathrm{C}$, com média mínima de $9,3^{\circ} \mathrm{C}$ em julho e média máxima de $24,7^{\circ} \mathrm{C}$ em janeiro, insolação de 2.212 horas anuais e umidade relativa do ar de 82\% (Moreno, 1961).

Foram avaliados quatro híbridos de sorgo de baixo tanino de comportamento agronômico diferenciado: AGX-213 (classificado como um híbrido forrageiro de porte intermediário); AG-2002 (híbrido forrageiro de porte alto); AGX-217; e AG-2005E (híbridos de duplo propósito).

O solo da área experimental é classificado como Podzólico vermelho-amarelo e pertence à unidade de mapeamento São Pedro. A unidade caracteriza-se por apresentar solos de textura superficial arenosa e friável, sendo naturalmente ácidos, pobres em matéria orgânica e, na maioria dos nutrientes, com baixa saturação de bases (Brasil, 1973).

O trabalho de pesquisa compreendeu o período de 21 de novembro de 1998 a 15 de agosto de 1999. As silagens dos híbridos de sorgo avaliados foram produzidas em uma área de 16 ha. As características de manejo e fertilidade de solo foram adequadas ao cultivo do sorgo, sendo 4 ha de lavoura para cada híbrido avaliado. As lavouras foram implantadas em 21-22/11/1998, em sistema de plantio direto na resteva da mistura forrageira aveia (Avena strigosa) e azevém (Lolium multiflorum), dessecada com Glifosato + Óleo Mineral. A plantadeira utilizada foi regulada com espaçamento entre linhas de $1 \mathrm{~m}$, profundidade de semeadura de $1 \mathrm{~cm}$ e distribuição de 16 a 18 sementes por metro linear. A adubação de base foi constituída de $300 \mathrm{~kg} / \mathrm{ha}$ de fertilizante NPK, na formulação 10-20-20 $\left(\mathrm{N}-\mathrm{P}_{2} \mathrm{O}_{5}-\mathrm{K}_{2} \mathrm{O}\right)$, conforme as CFRS/SC (1995), e em cobertura, 50 dias após o plantio, foram aplicados $150 \mathrm{~kg} /$ ha de uréia. A condução das lavouras de sorgo não envolveu práticas agronômicas de controle de plantas daninhas e enfermidades com produtos químicos ou práticas culturais.

As lavouras foram colhidas conforme recomen- 
dações sugeridas por Demarchi (1993), ou seja, o momento de ensilagem das plantas de sorgo de caráter duplo propósito (AGX-217 e AG-2005E) foi determinado entre os estádios reprodutivos de grão pastoso a farináceo, enquanto as plantas de sorgo de caráter forrageiro (AGX-213 e AG-2002) foi entre os estádios de grão farináceo a duro. O corte das plantas para o processo de ensilagem foi realizado com o auxílio de uma ensiladeira regulada com tamanho médio de picado de $1 \mathrm{~cm}$ e altura de corte média de $20 \mathrm{~cm}$. O material colhido foi transportado da área de cultivo, depositado em um local previamente nivelado e bem drenado, sendo compactado com auxílio de um trator em sistema de silos de superfície do tipo "torta”, sendo vedados e protegidos com lona de polietileno de três camadas.

Na ocasião da colheita para ensilagem, procedeu-se à avaliação produtiva, por intermédio da coleta de seis amostras ao acaso de plantas inteiras (material original) para cada híbrido de sorgo avaliado, cortadas manualmente a $20 \mathrm{~cm}$ do solo. Cada amostra constituiu-se de quatro metros lineares na linha de plantio. Posteriormente, as plantas amostradas foram pesadas e medidas individualmente. A adoção desse método permitiu determinar a estrutura física percentual das estruturas anatômicas da planta de sorgo, por meio da fragmentação dos componentes colmo, folhas e panícula.

A abertura dos silos tipo torta ocorreu, em média, 43 dias após a confecção da silagem. Cada silagem foi amostrada de forma homogênea e representativa, em três partes dos silos pré-determinadas (parte inicial, intermediária e final) e, assim como as amostras do material original, foram pesadas e pré-secas em estufa de ar forçado a $60^{\circ} \mathrm{C}$, por 72 horas. As amostras foram retiradas da estufa e pesadas novamente para determinação do teor de matéria parcialmente seca, sendo seqüencialmente processadas em moinho tipo Willey, com peneira de malha de $1 \mathrm{~mm}$.

Nas amostras pré-secas, determinaram-se a matéria seca total (MS), em estufa a $105^{\circ} \mathrm{C}$, e matéria mineral (MM), por incineração a $550^{\circ} \mathrm{C}$, em que o teor de matéria orgânica (MO) foi obtido por diferença (\% $\mathrm{MO}=100$ - MM) (AOAC, 1984). A digestibilidade in vitro da matéria orgânica (DIVMO) foi determinada conforme técnica descrita por Tilley \& Terry (1963); o teor de fibra em detergente neutro (FDN), segundo a técnica de Goering \& Van Soest (1970); e os teores de fibra em detergente ácido (FDA), lignina (LIG) e conteúdo de sílica da FDA (CZ-FDA), de acordo com AOAC (1995), em que a celulose foi obtida por diferença $(\mathrm{CEL}=\mathrm{FDA}-(\mathrm{LIG}+\mathrm{CZ}$ -
FDA)). Os nutrientes digestíveis totais (NDT) foram obtidos por intermédio da equação de regressão recomendada pela LATIN... (1974). Para o cálculo da energia digestível (ED, Mcal/kg de MS), utilizou-se a equação sugerida pelo ARC (1980), com base na digestibilidade in vitro da matéria orgânica (DIVMO, \%) e na matéria orgânica (MO, \%) das silagens, em que $\mathrm{ED}=(\mathrm{DIVMO} \times \mathrm{MO} \times 19) \div 4,18$, sendo calculado ainda, a partir desta, a energia metabolizável (EM), multiplicando a ED pelo fator 0,82 .

Para o comportamento produtivo e as estruturas anatômicas dos diferentes híbridos de sorgo, foi efetuada estatística descritiva amostral.

O delineamento experimental foi o inteiramente casualizado, composto por quatro tratamentos, com seis repetições para o material original e componentes da planta e três repetições para as silagens. Os dados coletados para cada parâmetro foram submetidos à análise de variância, por intermédio do programa estatístico SAS (1993), e as comparações entre as médias foram analisadas pelo teste de Tukey, a 5\%.

O modelo estatístico utilizado foi o seguinte:

$$
\mathrm{Y}_{\mathrm{ij}}=\mathrm{m}+\mathrm{SS}_{\mathrm{i}}+\mathrm{E}_{\mathrm{ij}}
$$

em que: $\mathrm{Y}_{\mathrm{ij}}=$ variáveis dependentes; $\mathrm{m}=$ média das observações; $\mathrm{SS}_{\mathrm{i}}=$ efeito da silagem de sorgo de ordem "i", sendo 1 (silagem de sorgo AGX-213), 2 (silagem de sorgo AG-2002), 3 (silagem de sorgo AGX-217) e 4 (silagem de sorgo AG-2005E); $\mathrm{E}_{\mathrm{ij}}=$ erro aleatório, assumindo distribuição normal média igual a zero e variância $\sigma^{2}$.

A comparação de médias entre material original e silagem foi realizada pelo teste " $t$ " de Student para amostras independentes a $5 \%$.

\section{Resultados e Discussão}

As médias da avaliação dos parâmetros produtivos dos híbridos de sorgo são apresentadas na Tabela 1 .

No momento da colheita para ensilagem, definiu-se o ciclo produtivo dos diferentes materiais genéticos, no qual se constata que o AG-2005E foi o híbrido de sorgo mais precoce com 125 dias de intervalo da semeadura (20/11/1998) à colheita (25/03/1999). Por outro lado, o AGX-213 colhido em 20/04/1999 caracterizou-se como um híbrido de ciclo tardio, totalizando 151 dias. Para os híbridos AG-2002 e AGX-217, observaram-se ciclos intermediários, com 140 e 141 dias, respectivamente.

Para as condições climáticas do Rio Grande do Sul, evidencia-se que o cultivo do AGX-213 se apresenta 
menos adequado para produção de silagem, devido ao seu ciclo tardio frente aos demais materiais testados.

$\mathrm{Na}$ análise descritiva amostral, a altura da planta foi superior para os híbridos forrageiros AG-2002 (2,59 m) e AGX-213 (2,33 m), comparados aos híbridos de duplo propósito AGX-217 (1,89 m) e AG-2005E $(1,72 \mathrm{~m})$, o que determinou o potencial produtivo de matéria verde e seca por unidade de área. Chielle et al. (2000) observaram, no ensaio da Rede Estadual SulRio-Grandense de sorgo silageiro 1999/2000, alturas variando de 2,31 a 2,35 m e 1,60 a 2,00 m, respectivamente, para os híbridos AG-2002 e AG-2005E.

Observa-se na Tabela 1 que o híbrido mais precoce (AG-2005E) apresentou menor produção de matéria seca.

Raupp et al. (2000), conduzindo um ensaio nacional de sorgo forrageiro para silagem 1999/2000, obtiveram alturas de planta de 2,20 e 1,92 m na região de Pelotas-RS e de 3,02 e 2,02 m na região de BagéRS, respectivamente, para os híbridos AG-2002 e AG-2005E, com produções de matéria verde na ordem de 45.981 e $32.844 \mathrm{~kg} / \mathrm{ha}$ e de 62.189 e $35.593 \mathrm{~kg} / \mathrm{ha}$, respectivamente, para os híbridos e as regiões citadas. Flaresso et al. (2000) verificaram que híbridos de sorgo mais tardios, como o AG-2002 com 128 dias, tenderam a apresentar maior altura $(3,43 \mathrm{~m})$ e maior rendimento $(21.657 \mathrm{~kg} / \mathrm{ha}$ de $\mathrm{MS})$ comparado aos híbridos mais precoces, como o AG-2005E, com 113 dias, com menor altura (1,94 m) e menor rendimento ( $14.691 \mathrm{~kg} / \mathrm{ha}$ de MS).

No presente trabalho, os híbridos forrageiros AG-2002 e AGX-213 apresentaram a mesma tendência observada por Flaresso et al. (2000), com maiores produções de matéria verde e matéria seca (MS) ensiláveis. Entretanto, estes valores de MS ficaram abaixo dos encontrados por Pereira et al. (1993), para os híbridos AG-2002 (18.000 kg/ha) e
AG-2005E (14.600 kg/ha), e aos relatados por Cândido et al. (2000) para os híbridos AGX-213 (14.620 kg/ha), AG-2002 (15.710 kg/ha)e AG-2005E (11.890 kg/ha), e por Gontijo Neto et al. (2000), com produções de $15.670,17.570$ e $12.030 \mathrm{~kg} / \mathrm{ha}$ para os híbridos AGX-213, AG-2002 e AG-2005E, respectivamente. Produções de MS/ha mais elevadas também foram relatadas por Silva \& Restle (1993) para o AG-2002 (14.291 kg) e AG-2005E (10.297 kg).

Segundo Zago (1991), o porte da planta de sorgo determina a proporção do componente panícula no material ensilado, classificando os híbridos de sorgo silageiros em graníferos (porte baixo), duplo propósito (porte intermediário) e forrageiros (porte alto).

Consta da Tabela 2 a participação de colmo, folhas e panícula nos híbridos de sorgo avaliados. Observa-se que o híbrido de duplo propósito AG-2005E apresentou maior porcentagem de panícula $(58,4 \%)$ e baixa porcentagem de colmo $(20,1 \%)$ e folhas $(21,5 \%)$, enquanto os híbridos forrageiros AG-2002 e AGX-213 apresentaram altas proporções do componente colmo (56,8 e 45,1\%, respectivamente). Já o híbrido AGX-217 apresentou uma distribuição mais equilibrada dos componentes colmo (36,3\%), folhas $(32,4 \%)$ e panícula $(31,3 \%)$, em relação aos demais híbridos avaliados, com base na matéria seca.

Por suas características fenotípicas, os híbridos de duplo propósito AGX-217 e AG-2005E apresentaram maiores proporções do componente panícula. Os híbridos AGX-213 e AGX-217 apresentaram maior participação do componente folhas frente aos híbridos AG-2002 e AG-2005E, tanto com base na matéria seca como na matéria verde. Este fato demonstra que a altura da planta não se relaciona com a massa foliar constituinte da planta de sorgo. Segundo Silva et al. (1999), estas comparações devem ser referidas com

Tabela 1 - Parâmetros de produção de híbridos de sorgo para produção de silagem Table 1 - Production parameters of sorghum hybrids for silage production

\begin{tabular}{lccc}
\hline $\begin{array}{l}\text { Parâmetros } \\
\text { Parameters }\end{array}$ & \multicolumn{2}{c}{$\begin{array}{c}\text { Híbridos de sorgo } \\
\text { Sorghum hybrids }\end{array}$} \\
\cline { 2 - 4 } & AGX-213 & AG-2002 & AGX-217 \\
\hline $\begin{array}{l}\text { Ciclo, dias para colheita } \\
\begin{array}{l}\text { Aycle, days to harvest } \\
\text { Altura da planta, } \mathrm{m}\end{array}\end{array}$ & 151 & 140 & 141 \\
$\begin{array}{l}\text { Plant height, } m \\
\text { Produção matéria verde, } \mathrm{kg} / \mathrm{ha}\end{array}$ & 2,33 & 2,59 & 1,89 \\
$\begin{array}{l}\text { Fresh matter production, } \mathrm{kg} / \mathrm{ha} \\
\text { Produção matéria seca, } \mathrm{kg} / \mathrm{ha} \\
\text { Dry matter production, } \mathrm{kg} / \mathrm{ha}\end{array}$ & 33.454 & 39.563 & 25.375 \\
\hline
\end{tabular}


base na matéria seca, pois os teores de MS dos componentes da planta são variáveis, conforme a interação genótipo/ambiente, atuando sobre o acúmulo de matéria seca da planta inteira.

Flaresso et al. (2000) consideram que a panícula é o componente mais importante para produção de silagem de alta energia, destacando em seus estudos o híbrido AG-2005E, com 47,4\% de panícula, 15,4\% de folhas e $35,0 \%$ de colmo. Os mesmos autores também consideram o componente colmo como o principal responsável pela produção de silagens de menor valor nutritivo, devido à sua baixa qualidade nutricional, destacando o híbrido AG-2002 com 62,2\% de colmo, $11,8 \%$ de folhas e $22,7 \%$ de panícula. Segundo Zago (1991), as empresas de melhoramento estão desenvolvendo híbridos que tenham bom equilíbrio entre colmo, folhas e panícula, para que se possa aliar uma boa produtividade de matéria seca a um bom valor nutritivo. No entanto, os critérios para desenvolvimento e/ou seleção de híbridos de sorgo para produção de silagem não devem se limitar apenas às características fenotípicas dos materiais, mas considerar a eficiência alimentar e a resposta econômica dos animais, frente às suas exigências nutricionais. Mondadori et al. (2000), trabalhando com os híbridos AG-2002 e AG-2005E, verificaram na composição física da planta valores de 50,6;19,0; e $30,4 \%$ e 37,$2 ; 16,8$; e $46,0 \%$, para os componentes colmo, folhas e panícula, respectivamente. Já Gontijo Neto et al. (2000), avaliando a composição física da planta de diferentes híbridos de sorgo, verificaram valores de 42,20; 20,72; e 37,08\% (AGX-213), 52,86;

Tabela 2 - Composição física percentual das estruturas anatômicas da planta de diferentes híbridos de sorgo para produção de silagem, com base na matéria seca (MS) e na matéria verde (MV)

Table 2 - Physical composition of the plant of different hybrids of sorghum, based on dry matter (DM) and fresh matter (FM)

\begin{tabular}{lcccc}
\hline $\begin{array}{l}\text { Híbrido } \\
\text { Hybrid }\end{array}$ & $\begin{array}{c}\text { Aptidão* } \\
\text { Aptitude }\end{array}$ & \multicolumn{2}{c}{$\begin{array}{c}\text { Composição física da planta } \\
\text { Physical composition of plant }\end{array}$} \\
\cline { 3 - 5 } & & $\begin{array}{c}\text { Colmo } \\
\text { Stem }\end{array}$ & $\begin{array}{c}\text { Folhas } \\
\text { Leaves }\end{array}$ & $\begin{array}{c}\text { Panícula } \\
\text { Panicle }\end{array}$ \\
\cline { 3 - 5 } & & \multicolumn{3}{c}{$\%$ MS (MV) } \\
AGX-213 & F & $45,1(50,2)$ & $30,3(33,2)$ & $24,6(16,6)$ \\
AG-2002 & F & $56,8(63,6)$ & $18,9(21,6)$ & $24,3(14,8)$ \\
AGX-217 & DP & $36,3(41,4)$ & $32,4(35,4)$ & $31,3(23,2)$ \\
AG-2005E & DP & $20,1(33,4)$ & $21,5(26,8)$ & $58,4(39,8)$ \\
\hline
\end{tabular}

${ }^{\star} \mathrm{F}=$ híbrido forrageiro e DP = híbrido duplo propósito.

${ }^{*} F=$ forage hybrid and $D P=$ double purpose hybrid.

R. Bras. Zootec., v.31, n.1, p.293-301, 2002 (suplemento)
16,96; e 30,18\% (AG-2002) e 29,86; 18,72; e 51,42\% (AG-2005E), respectivamente, para os componentes físicos colmo, folhas e panícula.

Os diferentes híbridos de sorgo testados apresentaram teores de MS diferentes entre si $(\mathrm{P}<0,05)$ no material analisado, antes e após o processo de ensilagem (Tabela 3). A variação encontrada foi de 26,38 a $35,90 \%$ no material original e de 26,79 a $35,50 \%$ na silagem, respectivamente, para os híbridos AG-2002 e AG-2005E, com valores intermediários aos híbridos AGX-213 e AGX-217.

$\mathrm{Na}$ comparação dos teores de MS entre material original e silagem de cada híbrido de sorgo avaliado, houve similaridade nos valores encontrados $(\mathrm{P}>0,05)$, sendo semelhante a resultados de outros autores, que demonstraram igualdade ou pequenas alterações na comparação desta variável antes e após o processo de ensilagem (Rodriguez et al., 1999; Pedroso et al., 2000; Pesce et al., 2000b).

Segundo Pesce et al. (2000a), o teor de MS da silagem de híbridos de sorgo é igual ou superior ao do respectivo material original. $\mathrm{O}$ aumento do teor de MS com a ensilagem pode ocorrer por fatores de ordem técnica, ligados à regulagem da ensiladeira na colheita, à distância de transporte entre a lavoura e o silo de armazenamento, ao tempo de enchimento, ao sistema de compactação e à vedação do silo no decorrer do processo de confecção da silagem. De acordo com Van Soest (1994), o acréscimo no teor de MS ocorre principalmente pela formação e perda de efluentes na fase fermentativa da massa ensilada.

Os teores de fibra em detergente neutro (FDN) e fibra em detergente ácido (FDA) da planta inteira antes da ensilagem e da silagem encontram-se na Tabela 3. Houve semelhança $(\mathrm{P}>0,05)$ entre os teores de FDN das silagens avaliadas. Porém, foi constatada diferença $(\mathrm{P}<0,05)$ entre os teores de FDN e FDA dos híbridos de sorgo no momento da ensilagem.

Os teores de FDN das silagens não diferiram $(\mathrm{P}<0,05)$, variando numericamente de 54,27\% (AG-2005E) a $58,27 \%$ (AGX-213), valores próximos aos relatados por Borges et al. (1997), trabalhando com híbridos de porte alto $(56,60$ a $59,75 \%)$, e Pesce et al. (2000b), em um comparativo de 20 híbridos de portes médio e alto pertencentes ao ensaio nacional (53,6 a 59,3\%), e acima dos citados por Borges et al. (1999), com híbridos de porte baixo (44,59 a 49,07\%).

Conforme Silva et al. (1999), fica evidente a diminuição nas concentrações de FDN com o aumento da participação do componente panícula na composição 
final da planta. Em situação inversa, o híbrido forrageiro AG-2002 de porte alto $(2,59 \mathrm{~m})$, associado à participação de $56,8 \%$ do componente físico estrutural anatômico colmo da planta, conferiu igual FDN e maior FDA na silagem em relação ao AG-2005E, indicando menor valor nutritivo do alimento. Silva \& Restle (1993) relataram valor similar de FDA para silagem de AG-2005E (28,78\%) e valor superior para silagem de AG-2002 (42,72\%).

Observa-se que os teores de FDN e FDA da silagem, quando comparados ao respectivo material original, foram semelhantes $(\mathrm{P}>0,05)$ para os híbridos AGX-217 e AG-2005E ou superior $(\mathrm{P}<0,05)$ para o AG-2002, sugerindo que o êxito da ocorrência de hidrólise de algum componente da FDN foi mínimo durante a ensilagem, principalmente a hemicelulose. Para os teores de hemicelulose na silagem e no material original, bem como entre os teores médios do material original e silagem, não houve diferença $(\mathrm{P}>0,05)$.
Segundo Van Soest (1994), a fração fibrosa do material ensilado pode ser acrescida percentualmente em condições de intensa formação de efluentes ocorridas durante o processo fermentativo, onde os compostos solúveis em água são aumentados ou reduzidos proporcionalmente à fração fibrosa na silagem pela formação de ácidos de fermentação. Analisando-se os resultados da Tabela 3, contata-se que os teores de FDN e FDA foram aumentados $(\mathrm{P}<0,05)$ na silagem do híbrido forrageiro AG-2002 em relação ao respectivo material original, devido à formação de efluentes no silo, em virtude da alta umidade do material original (26,38\% MS), constituindo-se, segundo Nussio (1992), em um parâmetro indesejável para adequada fermentação da massa ensilada. Já Silva et al. (1999), trabalhando com sorgos de portes baixo, médio e alto, observaram que a ensilagem provocou redução significativa nos teores de FDN, FDA, hemicelulose e celulose.

Tabela 3 - Teores de matéria seca (MS) e conteúdo de fibra em detergente neutro (FDN), fibra em detergente ácido (FDA), celulose (CEL), lignina (LIG) e cinzas totais na FDA (CZ-FDA) do material original (planta) e da silagem de diferentes híbridos de sorgo

Table 3 - Contents of total dry matter (DM) and contents of neutral detergent fiber (NDF), acid detergent fiber (ADF), cellulose (CEL), lignin (LIG) and total ash (TA) in the fresh material (plant) and silages of different sorghum hybrids

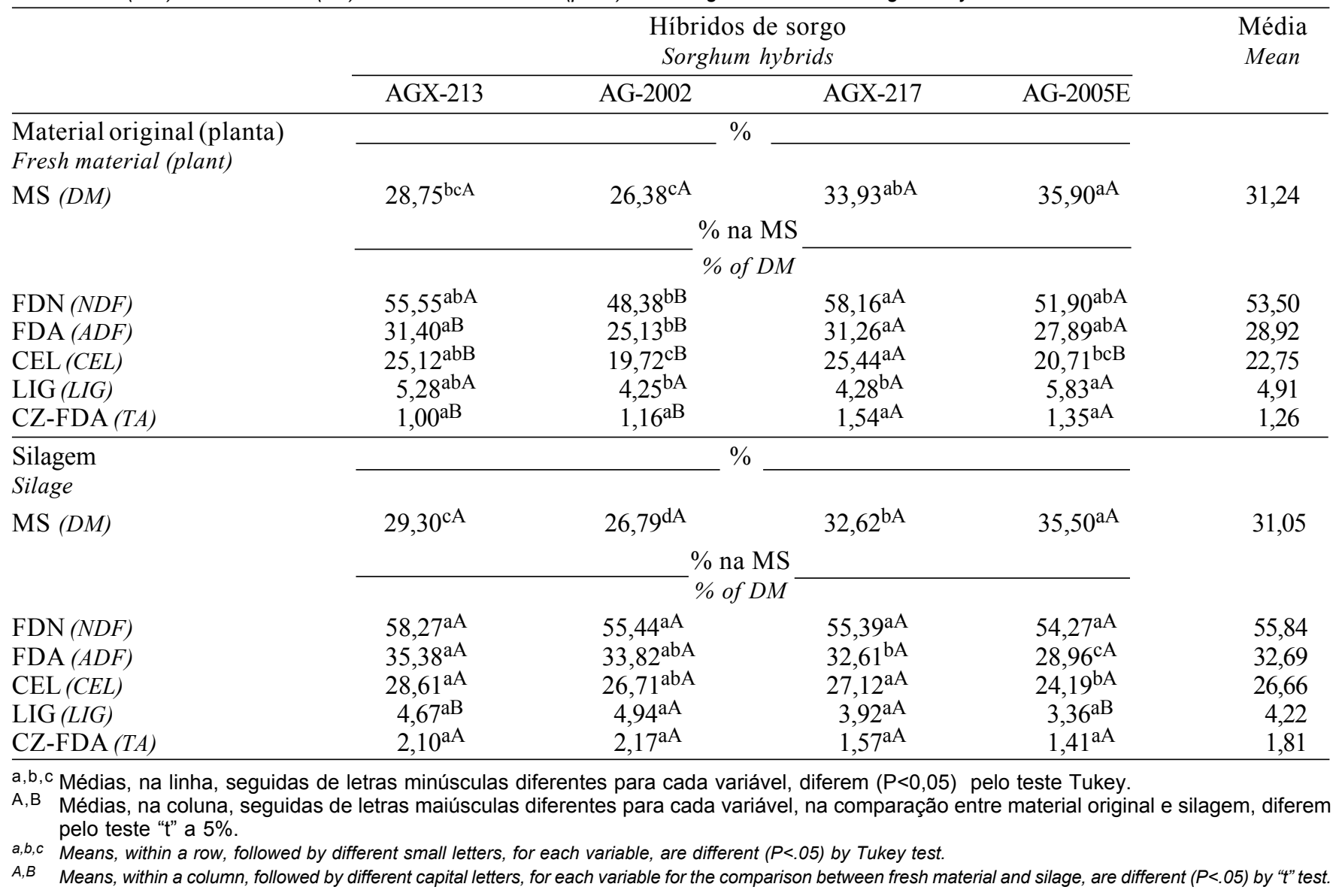

R. Bras. Zootec., v.31, n.1, p.293-301, 2002 (suplemento) 
No presente trabalho, observou-se que os constituintes da parede celular no material original não configuraram um comportamento regular e/ou semelhante entre os híbridos de sorgo avaliados após o processo de ensilagem. Pesce et al. (2000b) avaliaram os teores dos constituintes da parede celular da planta de 20 híbridos de sorgo e concluíram que os teores médios de FDN, FDA, CEL e LIG, determinados no material original, foram reduzidos após o processo de ensilagem, enquanto os teores de cinzas totais da FDA foram acrescidos. Porém, ao analisarem as médias individuais dos 20 híbridos de sorgo, verificou-se que nem todos apresentaram o mesmo comportamento. Assim, sugere-se que mais trabalhos de pesquisa sejam realizados a respeito do comportamento dos constituintes fibrosos da planta após o processo de ensilagem.

Também, deve-se considerar que o comportamento irregular observado na comparação entre material original e silagem dos híbridos testados, para os teores dos constituintes da porção fibrosa da planta, pode ter ocorrido pela participação indesejável de plantas de capim arroz (Echinochloa cruspavonis Schult.) na massa ensilada, em decorrência do sistema de colheita empregado, pois o método de amostragem das plantas inteiras no momento da ensilagem foi manual e desprezou as plantas infestantes presentes na área de cultivo.

A maioria dos trabalhos de pesquisa que avaliaram o valor nutritivo ou a qualidade da silagem de híbridos de sorgo (Bernardino et al., 1997; Borges et al., 1997; Rodriguez et al., 1998; Gonçalves et al., 1998, 1999; Pesce et al., 2000b) foi realizada em silos experimentais de PVC, que podem não refletir a realidade do processo de ensilagem e a presença de plantas invasoras de lavouras com relação aos silos confeccionados convencionalmente. Gonçalves et al. (1999) e Pesce et al. (2000a), avaliando híbridos de sorgo ensilados em silos de PVC, atribuíram a inexistência aparente de fermentações secundárias e as pequenas variações ocorridas com o processo de fermentação dos híbridos estudados ao tipo de silo utilizado ou ao tipo de vedação empregada.

$\mathrm{Na}$ Tabela 3 encontram-se também os teores de celulose (CEL), lignina (LIG) e cinzas (CZ-FDA) dos híbridos de sorgo avaliados nas formas de material original e silagem.

$\mathrm{Na}$ análise dos constituintes da parede celular da silagem, os teores de lignina e cinzas da FDA foram similares $(\mathrm{P}>0,05)$ entre os híbridos avaliados. No entanto, observou-se diferença significativa $(\mathrm{P}<0,05)$ quanto aos teores de celulose, variando de 24,19 (AG-2005E) a 28,61\% (AGX-213). Os valores de celulose da silagem obtidos no presente trabalho encontram-se acima dos relatados por Borges et al. (1997), trabalhando com híbridos de porte alto $(21,94$ a 23,05\%), e Borges et al. (1999), com híbridos de porte baixo (20,10 a 22,69\%), e próximos ou abaixo dos relatados por Pesce et al. (2000b), com híbridos de portes médio e alto $(27,0$ a $30,0 \%)$.

No material original, observou-se similaridade $(\mathrm{P}>0,05)$ somente para os teores de cinzas da FDA, enquanto os teores de celulose e lignina diferiram $(\mathrm{P}<0,05)$ entre os híbridos de sorgo testados. Observa-se que os maiores teores de lignina $(\mathrm{P}>0,05)$ da planta de sorgo no momento da ensilagem foram dos híbridos AG-2005E (5,83\%) e AGX-213 (5,28\%), em relação aos híbridos AGX-217 (4,28\%) e AG-2002 (4,25\%). Pesce et al. (2000b), na comparação de 20 híbridos de sorgo de porte médio e alto, encontraram teores de lignina variando de 4,0 a 5,4 no material original.

Segundo Nussio (1992), a explicação da variação dos teores de fração fibrosa da planta está na análise de cortes histológicos do colmo destes materiais com características de comportamento agronômico diferenciado, no qual se identificam agrupamentos de células de menor ou maior tamanho individual, resultante de programas de melhoramento genético, para aumentar a resistência do colmo ao acamamento e agentes patogênicos.

Houve diferença $(\mathrm{P}<0,05)$ na comparação dos teores de celulose, lignina e cinzas da FDA entre material original e massa ensilada. Van Soest (1994) afirma que as frações celulose e lignina se mantêm constantes e estáveis na fase fermentativa da massa ensilada e que estas frações somente serão decrescidas com a presença de fungos aeróbicos. Pesce et al. (2000b), trabalhando com híbridos de sorgo de portes médio e alto, e Borges et al. (1999), com híbridos de porte baixo contendo diferentes teores de tanino e de umidade no colmo, comprovaram esta afirmação, quando compararam material original e a respectiva silagem.

Na Tabela 4 são apresentados os parâmetros relativos à digestibilidade dos diferentes híbridos de sorgo. Não houve diferença $(\mathrm{P}>0,05)$ entre as silagens quanto aos teores de MO. No entanto, observou-se variação numérica nos teores de MO e DIVMO, sendo explicado pelas características fenóticas dos materiais testados (Tabela 2), em que as porcentagens dos componentes estruturais anatômicos da planta do sorgo variaram conforme o comportamento produtivo dos mesmos. 
Na comparação das silagens (Tabela 4), o NDT foi superior $(\mathrm{P}<0,05)$ para o híbrido AG-2005E $(62,20 \%)$ em relação aos híbridos AG-2002 (56,77\%) e AGX-213 (56,40\%), enquanto o AGX-217 (60,05\%) foi semelhante $(\mathrm{P}>0,05)$ a todos os híbridos testados. Santos (1996), trabalhando com silagens produzidas com e sem adubação de base, encontrou para o híbrido AG-2002 um valor para o NDT de 60,93\%.

$\mathrm{O}$ valor nutritivo da silagem também pode ser analisado pela concentração de energia digestível e/ou metabolizável, expresso em Mcal/kg de matéria seca. Não foi observada diferença $(\mathrm{P}>0,05)$ na con- centração energética da massa ensilada para os diferentes híbridos de sorgo. A silagem do híbrido AG-2005E, numericamente, concentrou maiores quantidades de energia por $\mathrm{kg}$ de matéria seca ensilada, comparativamente às demais silagens avaliadas, o que possibilita inferir que este material apresenta maior valor nutritivo ou maior concentração de nutrientes disponíveis ao animal durante a digestão. Silva \& Restle (1993) verificaram diferença $(\mathrm{P}=0,0211)$ para ED entre as silagens de AG-2005E (2,23 Mcal/kg de MS) e AG-2002 (1,89 Mcal/kg de MS), mas com valores inferiores aos encontrados no presente experimento.

Tabela 4 - Teores médios de matéria orgânica (MO), digestibilidade in vitro da matéria orgânica (DIVMO), nutrientes digestíveis totais (NDT), energia digestível (ED) e energia metabolizável (EM), com base na matéria seca total, de silagens de diferentes híbridos de sorgo

Table 4 - Average contents of organic matter (OM), in vitro organic matter digestibility (IVOMD), total digestible nutrients (TDN), digestible energy (DE) and metabolizable energy (ME), based on total dry matter, of the silages of different sorghum hybrids

\begin{tabular}{|c|c|c|c|c|c|}
\hline \multirow[t]{2}{*}{$\begin{array}{l}\text { Parâmetros } \\
\text { Parameters }\end{array}$} & \multicolumn{4}{|c|}{$\begin{array}{l}\text { Híbridos de sorgo } \\
\text { Sorghum hybrids }\end{array}$} & \multirow[t]{2}{*}{$\begin{array}{l}\text { Média } \\
\text { Mean }\end{array}$} \\
\hline & AGX-213 & AG-2002 & AGX-217 & AG-2005E & \\
\hline & \multicolumn{4}{|c|}{$\%$ na MS } & \\
\hline $\mathrm{MO}(O M)$ & $95,02^{\mathrm{a}}$ & $93,71^{\mathrm{a}}$ & $94,69^{\mathrm{a}}$ & $95,37^{\mathrm{a}}$ & 94,70 \\
\hline NDT $(T D N)$ & $56,40^{\mathrm{b}}$ & $56,77^{b}$ & $60,05^{\mathrm{ab}}$ & $62,20^{\mathrm{a}}$ & 58,86 \\
\hline DIVMO (IVDMO) & $54,28^{\mathrm{a}}$ & $50,40^{\mathrm{a}}$ & $53,77^{\mathrm{a}}$ & $57,87^{\mathrm{a}}$ & 54,08 \\
\hline \multirow[t]{3}{*}{ NDT $(T D N)$} & $56,40^{\mathrm{b}}$ & $56,77^{\mathrm{b}}$ & $60,05^{\mathrm{ab}}$ & $62,20^{\mathrm{a}}$ & 58,86 \\
\hline & \multirow{2}{*}{\multicolumn{5}{|c|}{$\begin{array}{c}\text { Mcal/ } \mathrm{kg} \text { de MS } \\
\text { Mcal/kg of DM }\end{array}$}} \\
\hline & & & & & \\
\hline $\mathrm{ED}(D E)$ & $2,344^{\mathrm{a}}$ & $2,149^{\mathrm{a}}$ & $2,313^{\mathrm{a}}$ & $2,508^{\mathrm{a}}$ & 2,329 \\
\hline $\mathrm{EM}(M E)$ & $1,922^{\mathrm{a}}$ & $1,762^{\mathrm{a}}$ & $1,896^{\mathrm{a}}$ & $2,057^{\mathrm{a}}$ & 1,909 \\
\hline
\end{tabular}

a,b Médias, na linha, seguidas de letras minúsculas diferentes para cada variável, diferem $(P<0,05)$ pelo teste Tukey.

$a, b$ Means, within a row, followed by different small letters, for each variable, are different $(P<.05)$ by Tukey test.

\section{Conclusões}

Os híbridos forrageiros AGX-213 e AG-2002 destacaram-se pelo maior potencial produtivo de massa verde e massa seca ensilável por unidade de área comparativamente aos híbridos de duplo propósito AGX-217 e AG-2005E.

O híbrido AG-2005E conferiu maior valor nutritivo à silagem, devido à maior porcentagem do componente panícula na estrutura da planta.

\section{Literatura Citada}

ALMEIDA FILHO, S.L.; FONSECA, D.M.; GARCIA, R. et al. Características agronômicas de cultivares de milho (Zea mays L.) e qualidade dos componentes e da silagem. Revista Brasileira de Zootecnia, v.28, n.1, p.7-13, 1999.
AGRICUltural RESEARCH COUNCIL - ARC. The nutrients requirements of ruminants livestock. London: Technical Review by on Agricultural Research Council Working, 1980.351p.

ASSOCIATION OF OFFICIAL ANALYTICAL CHEMISTS AOAC. Official methods of analysis. 14.ed. Washington, D.C., 1984. $1141 \mathrm{p}$.

ASSOCIATION OF OFFICIAL ANALYTICAL CHEMISTS AOAC. Official methods of analysis. 16.ed. Washington, D.C.: 1995. 1094p.

BERNARDINO, M.L.A.; RODRIGUEZ, N.M.; SANTANA, A.A.C. Silagem de sorgo de porte médio com diferentes teores de tanino e suculência no colmo. I. Nitrogênio amoniacal, pH e perdas de matéria seca. Pesquisa Brasileira de Medicina Veterinária e Zootecnia, v.49, n.2, p.213-223, 1997.

BORGES, A.L.C.C.; GONÇALVES, L.C.; RODRIGUEZ, N.M. et al. Qualidade de silagens de híbridos de sorgo de porte alto, com diferentes teores de tanino e umidadeno colmo. Pesquisa Brasileira de Medicina Veterinária e Zootecnia, v.49, n.4, p.441-452, 1997. BORGES, A.L.C.C.; GONÇALVES, L.C.; NOGUEIRA, F.S. et al. Silagem de sorgo de porte baixo com diferentes teores de tanino e de umidade no colmo. II - Alterações nos carboidratos 
durante a fermentação. Arquivo Brasileiro de Medicina Veterinária e Zootecnia, v.51, n.5, p.491-497, 1999.

BRASIL. Ministério da Agricultura. Levantamento de reconhecimento dos solos do Estado do Rio Grande do Sul. Recife. Departamento Nacional de Pesquisa Agropecuária - Divisão de Pesquisas Pedológicas, 1973. 430p. (Boletim Técnico, 30).

BRONDANI, I.L.; ALVES FILHO, D.C.; BERNARDES, R.A.C. Silagem de alta qualidade. In: RESTLE, J. (Ed.) Eficiência na produção de bovinos de corte. Santa Maria: Universidade Federal de Santa Maria, 2000. p.185-204.

CÂNDIDO, M.J.D.; OBEID, J.A.; PEREIRA, O.G. et al. Avaliação da produção e do valor nutritivo das silagens de cinco híbridos de sorgo. In: REUNIÃO ANUAL DA SOCIEDADE BRASILEIRA DE ZOOTECNIA, 37., 2000, Viçosa. Anais... Viçosa: Sociedade Brasileira de Zoootecnia, 2000. (CD Rom)

CHIELLE, Z.G.; TOMAZZI, D.J.; LOSSO, A.C. et al. Ensaio Sul-Rio-Grandense de sorgo silageiro 1999/2000, resultados da rede estadual. In: REUNIÃO TÉCNICA ANUAL DO SORGO, 28., REUNIÃO TÉCNICA ANUAL DO MILHO, 45., 2000, Pelotas. Anais... Pelotas: EMBRAPA - Clima Temperado, 2000. p.390-398.

COMISSÃO DE FERTILIDADE DO SOLO - CFRS/SC. Recomendações de adubação e calagem para os Estados do Rio Grande do Sul e Santa Catarina. 3.ed. Passo Fundo: SBCS-Núcleo Regional Sul, 1995. 223p.

DEMARCHI, J.J.A.A. Produção, valor nutritivo e características do sorgo (Sorghum bicolor L. Moench), colhido em cinco estádios de maturação, e de suas silagens. Piracicaba: Escola Superior de Agricultura “Luiz de Queiroz”, 1993.230p. Dissertação (Mestrado em Zootecnia) - Escola Superior de Agricultura "Luiz de Queiroz", 1993.

EIFERT, E.C. Silagens de sorgo e de triticale associadas a níveis de concentrado para alimentação de terneiros de corte desmamados precocemente. Santa Maria: Universidade Federal de Santa Maria, 2000. 150p. Dissertação (Mestrado em Zootecnia) - Universidade Federal de Santa Maria, 2000.

FLARESSO, J.A.; GROSS, C.D.; ALMEIDA, E.X. Cultivares de milho (Zea mays L.) e sorgo (Sorghum bicolor (L.) Moench.) para ensilagem no Alto Vale do Itajaí, Santa Catarina. Revista Brasileira de Zootecnia, v.29, n.6, p.1608-1615, 2000.

GOERING, H.K.; VAN SOEST, P.J. Forage fiber analysis: apparatus reagents, procedures and some applications. Local: Agricultural Hantbook, 1970. 379p.

GONÇALVES, L.C.; BORGES, A.L.C.C.; RODRIGUEZ, N.M. et al. Silagens de sorgo de porte alto com diferentes teores de tanino e de umidade no colmo. IV - Digestibilidade in vitro da matéria seca. Arquivo Brasileiro de Medicina Veterinária e Zootecnia, v.50, n.2, p.167-170, 1998.

GONÇALVES, L.C.; RODRIGUEZ, N.M.; NOGUEIRA, F.S. et al. Silagem de sorgo de porte baixo com diferentes teores de tanino e de umidade no colmo. III - Quebra de compostos nitrogenados. Arquivo Brasileiro de Medicina Veterinária e Zootecnia, v.51, n.6, p.571-576, 1999.

GONTIJO NETO, M.M.; OBEID, J.A.; PEREIRA, O.G. et al. Avaliação de características agronômicas de cinco híbridos de sorgo (Sorghum bicolor (L.) Moench). In: REUNIÃO ANUAL DA SOCIEDADE BRASILEIRA DE ZOOTECNIA, 37., 2000, Viçosa. Anais... Viçosa: Sociedade Brasileira de Zootecnia, 2000. (CD Room)

LATIN American tables of feed composition. Florida: University of Florida, 1974. p.11-16.

MONDADORI, R.G.; FRIZZO, A.; ROCHA, M.G. Comparação entre híbridos de sorgo para produção de silagem. In: REUNIÃO TÉCNICA ANUAL DO SORGO, 28.; REUNIÃO TÉCNICA ANUAL DO MILHO, 45., 2000, Pelotas. Anais... Pelotas: EMBRAPA - Clima Temperado, 2000. p.344-349.

MORENO, J.A. Clima do Rio Grande do Sul. Porto Alegre: Secretaria da Agricultura, 1961.41p.

NATIONAL RESEARCH COUNCIL - NRC. Nutrient requirements of domestic animals. 7.ed. Washington D.C.: National Academy Press, 1996.

R. Bras. Zootec., v.31, n.1, p.293-301, 2002 (suplemento)
NUSSIO, L.G. Produção de silagem de alta qualidade. In: REUNIÃO NACIONAL DE MILHO E SORGO, 19., 1992, Porto Alegre. Anais... Porto Alegre: Secretaria de Agricultura e Abastecimento, 1992. p.155-175.

PEDROSO, A.F.; FREITAS, A.R.; SOUZA, G.B. Efeito de inoculante bacteriano sobre a qualidade da silagem e perda de matéria seca durante a ensilagem de sorgo. Revista Brasileira de Zootecnia, v.29, n.1, p.48-52, 2000.

PEREIRA, O.G.; OBEID, J.A.; GOMIDE, J.A. et al. Produtividade de uma variedade de milho (Zea mays L.) e de três variedades de sorgo (Sorghum bicolor (L.) Moench) e o valor nutritivo de suas silagens. Revista Brasileira de Zootecnia, v.22, n.1, p.31-38, 1993.

PESCE, D.M.C.; GONÇALVES, L.C.; RODRIGUEZ, N.M. Porcentagem, perda e digestibilidade in vitro da matéria seca das silagens de 20 genótipos de sorgo. Arquivo Brasileiro de Medicina Veterinária Zootecnia, v.52, n.3, p.250-255, 2000a.

PESCE, D.M.C.; GONÇALVES, L.C.; SANTOS, J.A. Análise de vinte genótipos de sorgo (Sorghum bicolor (L.) Moench), de portes médio e alto, pertencentes ao ensaio nacional. Revista Brasileira de Zootecnia, v.29, n.4, p.978-987, 2000b.

RAUPP, A.A.A.; BRANCÃO, N.; PARTIFF, J.M.B. et al. Ensaio nacional de sorgo forrageiro para silagem em terras baixas, 1999/2000. In: REUNIÃO TÉCNICA ANUAL DO SORGO, 28; REUNIÃO TÉCNICA ANUAL DO MILHO, 45., 2000, Pelotas. Anais... Pelotas: Empresa Brasileira de Pesquisa Agropecuária, 2000. p.399-402.

RODRIGUEZ, N.M.; BORGES, A.L.C.C.; GONÇALVES, L.C. et al. Silagem de sorgo de porte alto com diferentes teores de tanino e de umidade no colmo. III - Quebra de compostos nitrogenados. Arquivo Brasileiro de Medicina Veterinária Zootecnia, v.50, n.2, p.161-165, 1998.

RODRIGUEZ, N.M.; GONÇALVES, L.C.; NOGUEIRA, F.A.S. et al. Silagem de sorgo de porte baixo com diferentes teores de tanino e de umidade no colmo. I- pH e teores de matéria seca e de ácidos graxos durante a fermentação. Arquivo Brasileiro de Medicina Veterinária Zootecnia, v.51, n.5, p.485-490, 1999.

SANTOS, L.A. Silagens de milho e sorgo: rendimento, qualidade e custo operacional. Pelotas: Universidade Federal de Pelotas, 1996. 131p. Dissertação (Mestrado em Produção Vegetal) - Universidade Federal de Pelotas, 1996.

SAS INSTITUTE. SAS Language reference. Version 6, Cary, NC: 1042p. 1993.

SILVA, L.C.R.; RESTLE, J. Avaliação do milho (Zea mays L.) e do sorgo (Sorghum bicolor L. Moench) para produção de silagem. In: REUNIÃO ANUAL DA SOCIEDADE BRASILEIRA DE ZOOTECNIA, 30., 1993, Rio de Janeiro. Anais... Rio de Janeiro: Sociedade Brasileira de Zootecnia, 1993. p.467.

SILVA, F.F.; GONÇALVES, L.C.; RODRIGUEZ, J.A.S. et al. Qualidade de silagens de híbridos de sorgo (Sorghum bicolor (L.) Moench) de portes baixo, médio e alto com diferentes proporções de colmo+folhas/panícula. 1. Avaliação do processo fermentativo. Revista Brasileira de Zootecnia, v.28, n.1, p.14-20, 1999 .

TILLEY, J.M.; TERRY, R.A. A two-stage technique for the in vitro digestion of forage crops. Journal of British Grassland Society, v.18, p.104-111, 1963.

VAN SOEST, P.J. Nutritional ecology of the ruminant. 2.ed. New York: Cornell University Press, 1994. 476p.

ZAGO, C.P. Cultura do sorgo para produção de silagem de alto valor nutritivo. In: PEIXOTO, A.M.; MOURA, J.C.; FARIA, V.P. (Eds.) SIMPÓSIO SOBRE NUTRIÇÃO DE BOVINOS, 4., 1991, Piracicaba. Anais... Piracicaba: Fundação de Estudos Agrários “Luiz de Queiroz”. 1991. p.169-217.

Recebido em: 30/03/01 Aceito em: 10/10/01 